\title{
Orientation Dependence of Low Cycle Fatigue Properties of a Ni-based Single Crystal Superalloy DD10
}

\author{
Fan Zhidong ${ }^{1,2}$, Li Ji ${ }^{1}$, Wang Dong ${ }^{2}$, Lou Langhong ${ }^{2}$, Zhang Jian $^{2}$ \\ ${ }^{1}$ Xi'an Thermal Power Research Institute Co., Ltd, Xi'an 710054, China; ${ }^{2}$ Institute of Metal Research, Chinese Academy of Sciences, \\ Shenyang 110016, China
}

\begin{abstract}
Low cycle fatigue (LCF) properties of a nickel-based single crystal (SX) superalloy DD10 with different orientation deviation angles from the [001] axis were investigated at $760{ }^{\circ} \mathrm{C}$ with an invariable total strain amplitude of $1.4 \%$. Results reveal that the LCF behaviors of DD10 exhibit a strong orientation-dependence. The fatigue life decreases apparently with the increment of the orientation deviation angle. For specimens with the same orientation deviation angle from the [001] axis, those on the [001]-[011] boundary exhibit a longer fatigue life than ones on the [001]-[ $\overline{1} 11]$ boundary. It is found that the orientation-dependence of fatigue life stems from the difference of accumulated plastic deformation per cycle. On the other hand, both of total stress amplitude and plastic strain amplitude show a reverse orientation-dependence compared with the fatigue life. However, the orientation deviation shows no influence on the model of fatigue crack initiation and subsequent propagation.
\end{abstract}

Key words: single crystal superalloy; DD10 alloy; orientation deviation; low cycle fatigue

Turbine blades in single crystal (SX) form are the most important development in the materials technology of advanced turbines, and the use of SX nickel-base superalloys has enabled to significantly increase the turbine inlet temperature ${ }^{[1-3]}$. The excellent attractive elevated temperature capability of SX superalloy is thought to be mainly due to the absolute elimination of the weakening grain boundaries of polycrystalline castings ${ }^{[4,5]}$. However, just due to the lack of grain boundaries, the SX superalloy exhibits highly anisotropic material mechanical properties ${ }^{[6]}$, especially in LCF behavior, which complicates life prediction methodology ${ }^{[7]}$. Therefore extensive work has been conducted in order to evaluate effects of orientation on LCF behavior for SX superalloys ${ }^{[6,8-15]}$.

Most relative studies focused on comparative studies of SX superalloys with crystal orientation near the three axes, namely [001], [011] and [ $\overline{1} 11]$. It's found that SX superalloys with orientation around the axis [001] usually have the longest fatigue life $\left(N_{\mathrm{f}}\right)$ and ones around the axis [1 111 have the shortest ${ }^{[7,9,15]}$. This orientation-dependence of fatigue behavior for SX superalloys is thought to be due primarily to Young's modulus of elasticity $(E)^{[9]}$. This viewpoint may be reasonable in high cycle fatigue, because the deformation is in the elastic region. However, it is not enough to consider only the difference in $E$ for LCF since the cyclic plastic deformation is alsoa major factor in governing the LCF life ${ }^{[15]}$.

SX superalloys along the axis [001] are usually favorable, due to excellent mechanical properties compared to those along [011] or [ $\overline{1} 11]$. Luckily, the axis [001] is also the preferred growth direction during directional solidification process $^{[1]}$. In practice, despite the preference for perfect alignment, the solidification direction of SX superalloy almost deviates from the axis [001] when a turbine blade is cast in single crystal form ${ }^{[4,16]}$. The kind of misorientation can't be avoided. This situation results in that a fraction of SX turbine blades have to be used in a condition that the centrifugal loading deviates away from the exact [001] orientation to a certain extent ${ }^{[1,16]}$. Corresponding degradation of mechanical properties can be expected ${ }^{[1,13,17-20]}$. Based on practical considerations and cost implications, a trade-off between

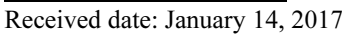

Foundation item: National Natural Science Foundation of China $(51631008,51101160)$

Corresponding author: Wang Dong, Ph. D., Professor, Institute of Metal Research, Chinese Academy of Sciences, Shenyang 110016, P. R. China, Tel: 0086-24-83970230, Fax: 0086-24-23971712, E-mail: dwang@imr.ac.cn 
orientation deviation and mechanical performance must always be made. This situation demands that attention should be paid to the influences of such misorientation on SX superalloy's properties at elevated temperatures, especially on LCF properties. In addition, the orientation deviation consists of two factors, namely the deviation angle $(\varphi)$ from the axis [001] and the deviation angle $(\theta)$ from the [001]-[011] boundary, just as illustrated in Fig.2a. Nevertheless there is lack of work on effects of the two factors of orientation deviation on LCF behaviors of SX superalloy, so corresponding in-depth studies are necessary.

The present work aims at obtaining an improved understanding of influences of orientation deviation degrees ( $\varphi$ and $\theta)$ on LCF properties of SX superalloys. In order to achieve this, LCF tests were conducted at $760{ }^{\circ} \mathrm{C}$ and with an invariable total strain amplitude of $1.4 \%$ for a nickel-based single crystal (SX) superalloy DD10 with different orientation deviationangles from the [001] axis.

\section{Experiment}

The experimental alloy used in this work is a first generation single crystal superalloy DD10, which contains $13 \mathrm{Cr}, 4 \mathrm{Co}$, 7.8( $\mathrm{Al}+\mathrm{Ti}), 11 \sim 13(\mathrm{Ta}+\mathrm{W}+\mathrm{Mo})$, with minor $\mathrm{C}$ and $\mathrm{B}$, and $\mathrm{Ni}$ in balance (weight percent). SX slabs with dimensions of $180 \mathrm{~mm}$ $\times 70 \mathrm{~mm} \times 20 \mathrm{~mm}$ were fabricated by a vacuum induction furnace with high rate solidification (HRS) technique.

All SX slabs received the same standard heat treatment, comprising a solution treatment at $1050{ }^{\circ} \mathrm{C}$ for $3 \mathrm{~h}$ in air and a two-step ageing treatment, first at $1100^{\circ} \mathrm{C}$ for $5 \mathrm{~h}$ and second at $870{ }^{\circ} \mathrm{C}$ for $24 \mathrm{~h}$, both followed by air-cooling. The heat treatment developed for DD10 produced a homogeneous distribution of cuboidal $\gamma^{\prime}$ particles, with size of about $0.4 \mu \mathrm{m}$ and volume fraction of about $65 \%$. The typical morphologies of $\gamma^{\prime}$ precipitates after heat treatment are shown in Fig.1, and no residual $\gamma / \gamma^{\prime}$ eutectics are visible.

The crystallographic orientation of each slab was then determined by Electron Back-scatter Diffraction (EBSD) in order to machine LCF specimens with particular crystallographic orientations. Samples were cut from slabs using electric discharge machine, and then machined into LCF specimens with $5 \mathrm{~mm}$ in diameter and $12 \mathrm{~mm}$ in gauge length. According to the crystal orientation in the triangle of the stereographic projection, samples were divided into three groups, just as illustrated in Fig.2b. Specimens around the axis [001] within $3^{\circ}$ belong to Group 1 (G1). The other specimens deviate away from the axis [001] from $8^{\circ}$ to $16^{\circ}$, and ones on the [001]-[011] boundary belong to Group 2 (G2) and the other ones on the [001]-[ $\overline{1} 11]$ boundary belong to Group 3 (G3).

A servo hydraulic testing machine was used to perform the fatigue tests at $760{ }^{\circ} \mathrm{C}$ with the total strain amplitude of $1.4 \%$. The strain rate was $5 \times 10^{-3} \mathrm{~s}^{-1}$, applied in a triangular waveform. The temperature fluctuation over the gauge length was maintained within $\pm 2{ }^{\circ} \mathrm{C}$; all the tests were performed in air. After

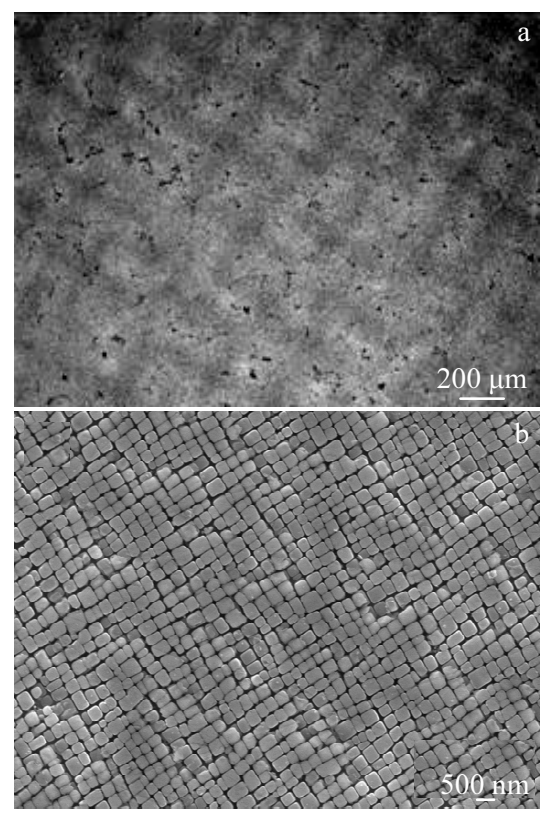

Fig. 1 OM (a) and SEM (b) microstructures of DD10 after solution heat treatment

LCF tests, fracture surfaces were examined by scanning electron microscopy (SEM).

\section{Results and Discussion}

\subsection{Fatigue life}

The LCF lives of SX DD10 with different orientation deviation angles are plotted in Fig. 3. Like most SX superalloys, an apparent orientation-dependence of fatigue life was observed for DD10 $0^{[10,13-15,18,21]}$. A sharp decrease in $N_{\mathrm{f}}$ was observed with the increment of $\varphi$. Besides, for specimens with the same $\varphi$, those on the [001]-[011] boundary exhibited a longer $N_{\mathrm{f}}$ than ones on the [001]-[1 11$]$ boundary. This was rarely reported in previous studies. Another point worth noting is that the decrease in $N_{\mathrm{f}}$ was much severer for the change of $\varphi$ than that of $\theta$, indicating that the influence of $\varphi$ on $N_{\mathrm{f}}$ is more evident than that of $\theta$.

The fatigue life behavior of DD10 was characterized by a slight scatter for specimens with the same crystal orientation. Similar scatter in fatigue life of SX superalloys were also
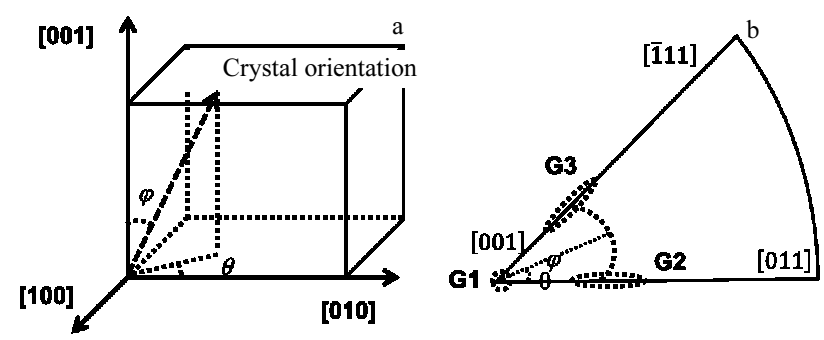

Fig.2 Illustration of specimens' crystal orientation 
observed in many other LCF tests in the intermediate temperature range $\mathrm{e}^{[9,13,22,23]}$.

\subsection{Cyclic stress response behavior}

The evolution of cyclic stress amplitude $\left(\Delta \sigma_{\mathrm{t}}\right)$ with respect to the number of cycles to failure for SX DD10 at $760{ }^{\circ} \mathrm{C}$ with $\Delta \varepsilon_{t} / 2=0.7 \%$ is plotted in Fig. 4 . For all specimens employed in the work, the alloy was observed to be cyclically hardened (increase in stress amplitude) within the first few cycles of straining. Furthermore, this relatively short duration of the initial cyclic hardening was followed by a long saturation stage (steady in stress amplitude). This cyclic stress trend is similar to that observed in many other SX superalloys' LCF tests at intermediate temperature range ${ }^{[15,22,24]}$. This indicates that the cyclic hardening/softening trend in this work is independent on the orientation deviation.

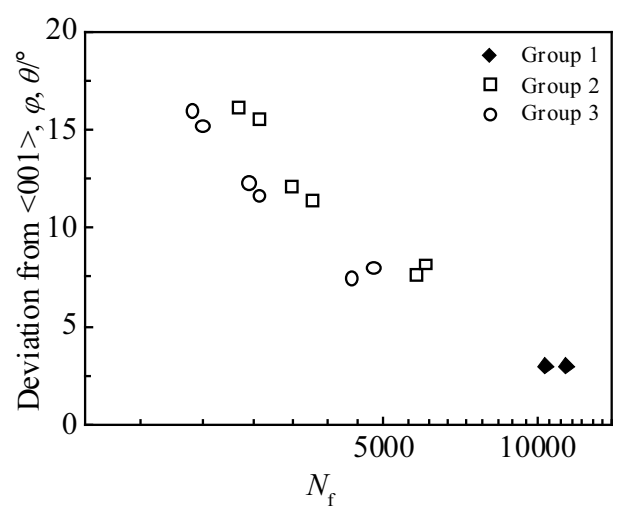

Fig. 3 Effect of $\varphi$ and $\theta$ on $N_{\mathrm{f}}$ at $760{ }^{\circ} \mathrm{C}$ with $\Delta \varepsilon_{\mathrm{t}} / 2=0.7 \%$

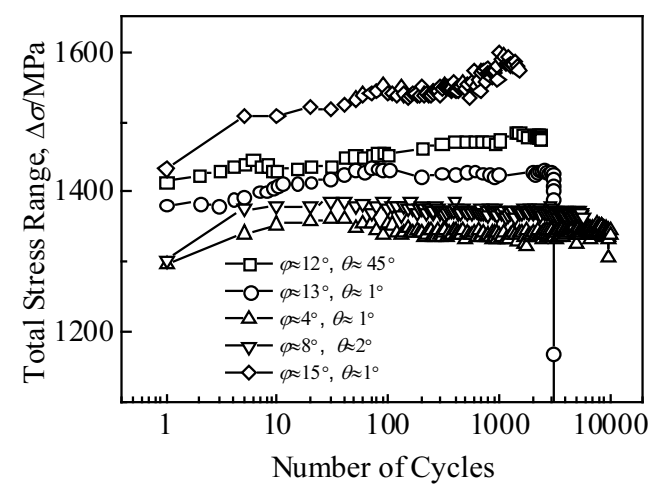

Fig. 4 Effect of orientation deviation on cyclic stress response behavior of alloy DD10 at $760{ }^{\circ} \mathrm{C}$ with $\Delta \varepsilon_{t} / 2=0.7 \%$

Another point worth noting is that the stress amplitude exhibited a strong dependence on the crystal orientation. Specimens from G1 held the lowest stress amplitude. Then $\Delta \sigma_{\mathrm{t}}$ increased apparently with the increment of $\varphi$. For specimens with the same $\varphi$, those on the [001]-[011] boundary exhibited a higher $\Delta \sigma_{\mathrm{t}}$ than ones on the [001]-[ $\left.\overline{1} 11\right]$ boundary. Obviously this orientation-dependence of $\Delta \sigma_{\mathrm{t}}$ is just reverse to that of fatigue life in this work.

\subsection{Fracture behavior}

Under test conditions in present work, the fracture surfaces are all characterized by one or more macroscopical cleavagelike facets inclined to the loading axis. This characteristic of stage I fracture surface is in good agreement with observations on many other SX superalloys under similar conditions ${ }^{[9,21,25-27]}$. Representative images of the fatigue fracture morphologies of specimens with different orientation deviation angles are listed in Fig.5. From the striation patterns, it can be affirmed that the incipient fatigue crack initiation is adjacent to the outer surface, and a small rough region of Stage II crack growth is found to be associated with the crack initiation origin for all specimens (Fig.5a and 5c). Further observation at higher magnification reveals that fatigue crack initiated at defects in subsurface, such as micro-pores (Fig.5b, 5d and 5f). Crack growth subsequently shifted to the Stage I mode on inclined planes. These dominant Stage I regions are macroscopically flat with a cleavage appearance, but displays a surface texture at higher magnification, as illustrated by the black arrow in Fig.5e. It can be concluded that no obvious orientationdependence was observed in the process of fatigue crack initiation or subsequently crack growth.

\section{Discussion}

In the present work, SX superalloy DD10 displays a strong orientation-dependence of fatigue life and total stress amplitude, but not of fracture model. Corresponding discussions were made in this part.

\subsection{Influence of orientation deviation on total stress amplitude}

The relationship between the total strain amplitude and total stress amplitude can be described by following equation ${ }^{[28]}$ :

$$
\Delta \varepsilon_{\mathrm{t}} / 2=\Delta \sigma_{\mathrm{t}} / 2 E_{(\theta, \varphi)}+\left(\Delta \sigma_{\mathrm{t}} / 2 K^{\prime}\right)^{1 / n^{\prime}}
$$

Where $E_{(\varphi, \theta)}$ is the Young's modulus for specimen with orientation deviation angle $(\theta$ and $\varphi), K^{\prime}$ is the cyclic strength coefficient and $n^{\prime}$ the cyclic strain-hardening exponent. In this work, the $\Delta \varepsilon_{\mathrm{t}}, K^{\prime}$ and $n^{\prime}$ in Eq.(1) are thought to be constant, and both of $K^{\prime}$ and $n^{\prime}$ are usually plus. In strain-controlled fatigue tests, the $\Delta \varepsilon_{\mathrm{t}}$ consists of the elastic strain amplitude $\left(\Delta \varepsilon_{\mathrm{e}}\right)$ and the plastic strain amplitude $\left(\Delta \varepsilon_{\mathrm{p}}\right)$. In this test, $\Delta \varepsilon_{\mathrm{p}}$ is extremely little comparison to $\Delta \varepsilon_{\mathrm{e}}$ due to a limited $\Delta \varepsilon_{\mathrm{t}}$ (Table 1). So the Eq. (1) can be further simplified into the equation:

$$
\Delta \varepsilon_{\mathrm{t}} / 2 \approx \Delta \sigma_{\mathrm{t}} / 2 E_{(\theta, \varphi)} \rightarrow \Delta \sigma_{\mathrm{t}} \approx \Delta \varepsilon_{\mathrm{t}} \cdot E_{(\theta, \varphi)}
$$

Obviously $\Delta \sigma_{\mathrm{t}}$, will change with $E_{(\varphi, \theta)}$ of SX superalloy DD10 in the same trend.

According to previous studies ${ }^{[29]}$, the Young's modulus of SX superalloy exhibits a strong dependence on the crystal orientation. It's thought that the relationship between $E_{(\varphi, \theta)}$ and crystal orientation for SX materials can be described by the following equation:

$$
E_{(\theta, \varphi)}^{-1}=S_{11}-\left(2 S_{11}-2 S_{12}-S_{44}\right) \sin ^{2} \varphi\left(\cos ^{2} \varphi+1 / 4 \sin ^{2} \varphi \sin ^{2} 2 \theta\right)
$$

where $S_{11}, S_{12}$, and $S_{44}$ are the elastic coefficients of the [001] crystal orientation, which are plus constants. Eq. (2) can be further simplified as following: 

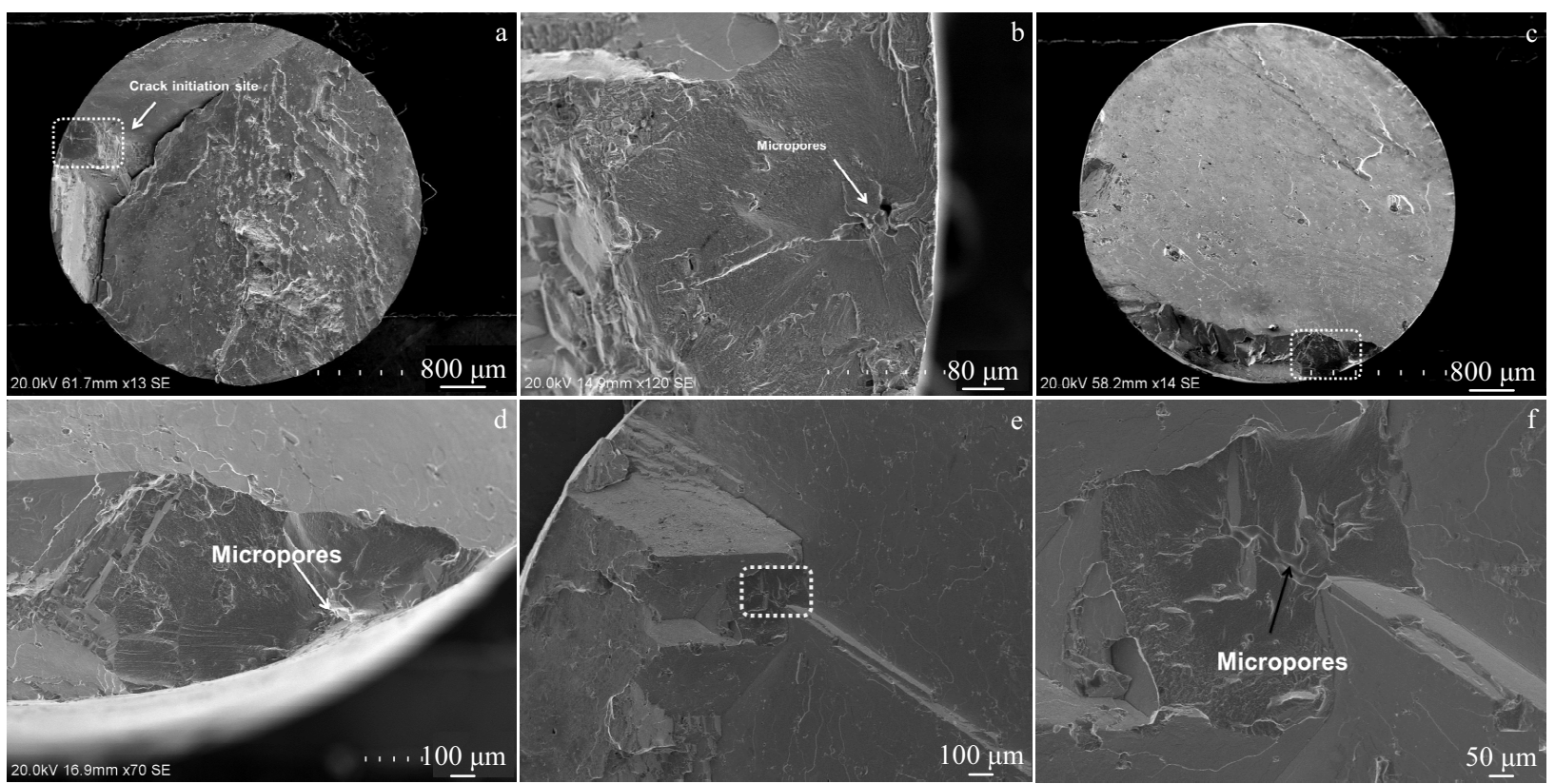

Fig.5 SEM images of fracture profile after LCF at $\Delta \varepsilon_{t} / 2=0.7 \%$ : (a, b) $\varphi \approx 12^{\circ}, \theta \approx 0$; (c, d) $\varphi \approx 12^{\circ}, \theta \approx 45^{\circ}$; (e, f) $\varphi \approx 15^{\circ}, \theta \approx 1^{\circ}$

$$
E_{(\theta, \varphi)}^{-1}=A-B \sin ^{2} \varphi\left(\cos ^{2} \varphi+1 / 4 \sin ^{2} \varphi \sin ^{2} 2 \theta\right)
$$

where $A$ equals to $S_{11}$, and $B$ equals to $2 S_{11}-2 S_{12}-S_{44}$. And the Young modulus of specimens can be expressed as follows:

$$
\begin{aligned}
& E_{\mathrm{G} 1} \approx \lim _{\varphi \rightarrow 0} E(\varphi, \theta)=1 / A \\
& E_{\mathrm{G} 2} \approx \lim _{\theta \rightarrow 0} E(\varphi, \theta)=1 /\left(A-B \sin ^{2} 2 \varphi\right) \\
& E_{\mathrm{G} 3} \approx \lim _{\theta \rightarrow 45^{\circ}} E(\varphi, \theta)=1 /\left[A-B\left(\sin ^{2} 2 \varphi+\sin ^{4} \varphi / 4\right)\right]
\end{aligned}
$$

where $E_{\mathrm{G} i}(i=1,2,3)$ refers to the Young's modulus of specimens from group 1, 2 and 3, respectively. In this work, $\varphi$ varied from $0^{\circ}$ to $15^{\circ}$, and so it's easily concluded that $E_{\mathrm{G} 1}<E_{\mathrm{G} 2}<E_{\mathrm{G} 3}$. Obviously $E_{(\varphi, \theta)}$ increases with the increment of deviation angle from the axis [001], and $E_{(\varphi, \theta)}$ of specimens on the [001]-[011] boundary is smaller than that on the [001]-[ $\overline{1} 11]$ boundary, just as $\Delta \sigma_{\mathrm{t}}$ does. Therefore the orientation-dependence of $\Delta \sigma_{\mathrm{t}}$ is practically due to influence of orientation on $E_{(\varphi, \theta)}$.

\subsection{Influence of orientation deviation on fatigue life}

The orientation-dependence of fatigue life for SX superalloy was thought to stem from the influence of orientation on $\Delta \sigma_{\mathrm{t}}$. In this work, fatigue life is found to be relatively insensitive to orientation on the stress amplitude basis (Fig.6), as same as in many previous studies ${ }^{[6,9,13-15]}$. The orientation-dependence of fatigue life observed on a total strain basis appears to be related to stress. Lightened by the discussion above, the orientation- dependence of $\Delta \sigma_{\mathrm{t}}$ is mainly due to the difference in $E$ resulted by change of crystal orientation. However, it is not enough to consider only the difference in $E$ for LCF since the cyclic plastic deformation is alsoa major factor in governing LCF life ${ }^{[15]}$.

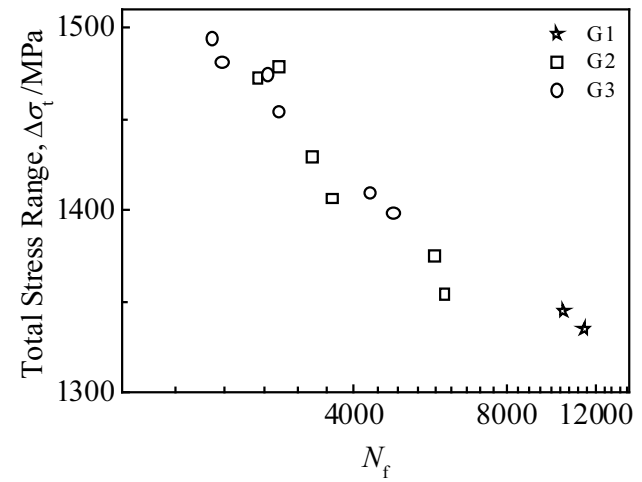

Fig. 6 Fatigue life behavior on the total stress range basis

According to the classic Eq. (8) ${ }^{[30]}$, the relationship between the plastic strain amplitude and the total stress amplitude can be described as follows.

$$
\Delta \sigma_{\mathrm{t}} / 2=K^{\prime}\left(\Delta \varepsilon_{\mathrm{p}} / 2\right)^{n^{\prime}}
$$

Where, both of $K^{\prime}$ and $n^{\prime}$ are plus. Based on the Eq.(8), $\Delta \varepsilon_{\mathrm{p}}$ will increase with $\Delta \sigma_{\mathrm{t}}$, and this rule was also proved in this work. Additionally in some studies involving effects of disorientation on tensile properties for SX superalloy, it's found that the yield stress decreases with the increase of dsorientation ${ }^{[1,2]}$, exhibiting a converse trend compared to $\Delta \sigma_{\mathrm{t}}$.

Through the strain-stress hysteresis loops at the $N_{\mathrm{f}} / 2$ cycle, data of plastic strain amplitude and corresponding $N_{\mathrm{f}}$ are listed in Table 1. It's observed that $\Delta \varepsilon_{\mathrm{p}}$ is smallest for orientations around the axis [001], and exhibited a decrease trend with the increment of deviation angles. Additionally $\Delta \varepsilon_{\mathrm{p}}$ on the [001]-[ $\overline{1} 11]$ boundary is bigger than that on the [001]-[011] boundary when $\varphi$ is constant. And a higher $\Delta \varepsilon_{\mathrm{p}}$ is companied 
Table 1 Plastic strain amplitude of DD10 at the saturation stage of LCF tests

\begin{tabular}{ccccc}
\hline & $\mathrm{G} 1$ & $\mathrm{G} 2\left(\varphi \approx 13^{\circ}\right)$ & $\mathrm{G} 3\left(\varphi \approx 12^{\circ}\right)$ & $\mathrm{G} 2\left(\varphi \approx 15^{\circ}\right.$ \\
\hline$\Delta \varepsilon_{\mathrm{p}} / \%$ & 0.0087 & 0.0174 & 0.0251 & 0.0798 \\
$N_{\mathrm{f}}$ & 10344 & 3613 & 2834 & 2579 \\
\hline
\end{tabular}

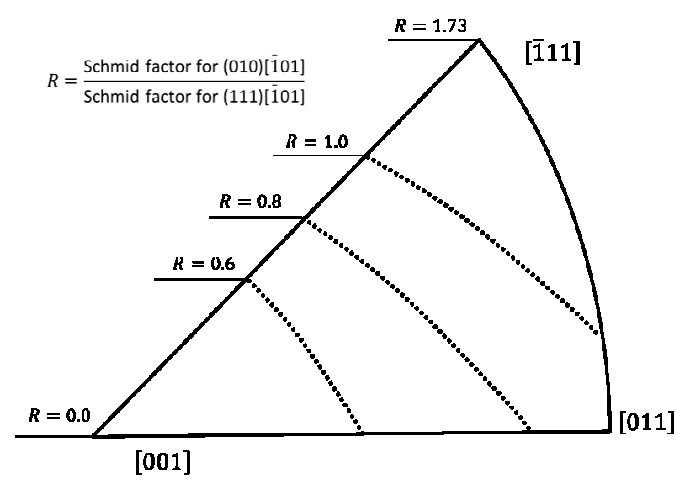

Fig. 7 Contours of equal Schmid factor ratio in the unite triangle

with a short $N_{\mathrm{f}}$ (Table 1). Therefore it can be concluded that the orientation-dependence of fatigue life is due to differences in plastic strain amplitudes.

The main possible source of the scatter in fatigue life in this work is the random distribution in micro-pore size. From analysis of fracture profile for failure specimens, the fatigue crack almost initiated at micro-pores in the vicinity of surface, as same as observed in many other LCF tests at intermediate temperatures $^{[9,12,21,23,24,31]}$. The fatigue life is thought to be sensitive to the micro-pore property ${ }^{[9,32]}$. Brundidge ${ }^{[32]}$ etc. found that the fatigue life of SX alloy René N5 at $538{ }^{\circ} \mathrm{C}$ is mainly influenced by the maximum size of micro-pore in specimens. Although the volume fraction of micro-pore in cast can be thought to be constant for casting under constant solidification parameters, the micro-pore size is randomly distributed. Relatively bigger micro-pores at subsurface will result in local stress concentration in a relatively shorter time, and subsequently induce the micro-crack vertical to the loading axis ${ }^{[32,33]}$. The general non-homogeneity of the micro-pore size results in the scatter observed in fatigue life.

\subsection{Influence of orientation deviation on fracture profile}

The fracture profiles were characterized by micro-pore initiation and Stage I propagation for all specimens in this work. No obvious orientation-dependence was observed in the fatigue crack initiation and subsequently propagation. This is due to that influencing factors on this process are barely affected by orientation deviation.

Temperature was the key factor influencing the fatigue crack initiation model. For most SX superalloys in LCF tests, the micro-pore initiation is common at intermediate temperature range $\mathrm{e}^{[9,12,21,23,24,27,32]}$, but the crack initiation will shift to the outer surface at higher temperature range, due to severe oxidation damage ${ }^{[9,21,27]}$. The fatigue crack subsequ- ently propagates along the primary slip planes at intermediate temperature range, so the type of activated slip systems is mainly influenced by the corresponding value of Schmid factor. The ratios of Schmid factors for cube slip system (010)[ $\overline{1} 01]$ and octahedral slip system (111)[ $\overline{1} 01]$ are illustrated in Fig.7. It can be concluded the octahedral slip system is predominant in this work since the orientation deviation angle from the [001] axis is limited, perhaps $16^{\circ}$ at most.

\section{Conclusions}

1) The fatigue life of DD10 around the [001] axis was longest, and then decreases with the increment of the orientation deviation angle. DD10 on the [001]-[011] boundary has a longer fatigue life than that on the [001]-[111] boundary. Both of the total stress amplitude and the plastic strain amplitude exhibit a same orientation-dependence but reverse to that of the fatigue life.

2) The fracture profile of DD10 shows no evidences of orientation-dependence. All specimens have a small region of Stage II crack growth associated with the crack initiation origin at micro-pores in the subsurface. Crack growth subsequently shifts to the Stage I mode on one or more [111] planes.

\section{References}

1 Matan N, Cox D C, Carter P et al. Acta Materialia[J], 1999, 47: 1549

2 Miao J S, Pollock T M, Jones J W. Acta Materialia[J], 2009, 57: 5964

3 Lu Xuping, Wen Zhixun, Yue Zhufeng et al. Rare Metal Materials and Engineering[J], 2015, 44(5): 1173 (in Chinese)

4 Reed R C. The Superalloys Fundamentals and Applications[M]. New York: Cambridge University Press, 2006

5 Sims C T, Stoloff N S, Hagel W C. Superalloys II[B], New York: John Wiley \& Sons, 1987

6 Li S, Ellison E, Smith D. The Journal of Strain Analysis for Engineering Design[J], 1994, 29: 147

7 Nx H, Zx W. International Journal of Fatigue[J], 2009, 31: 616

8 Jiao F, Bettge D, Osterle W et al. Acta Materialia[J], 1996, 44: 3933

9 Gabb T P, Gyda J, Miner R V. Metallurgical Transactions A[J], 1984, 17A: 497

10 Anton D. Acta Metallurgica[J], 1984, 32: 1669

11 Chieragatti R, Remy L. Materials Science and Engineering A[J], 1991, 141: 11

12 Defresne A, Remy L. Materials Science and Engineering A[J], 1990, 129: 45

13 Shi D Q, Huang J, Yang X G et al. International Journal of Fatigue[J], 2013, 49: 31

14 Arakere N K, Swanson G. Transactions of the ASME-AEngineering for Gas Turbines and Power[J], 2006, 124: 161 
15 Zhufeng Y, Xiande T, Zeyong Y et al. Applied Mathematics and Mechanics[J], 2000, 21: 415

16 McLean M. Directional Solidified Materials for High Temperature Service[M]. London: The Metals Society, 1983: 152

17 Zhang S H, Wang D, Zhang J L et al. Journal of Materials Science \& Technology[J], 2012, 28: 229

18 Lall C, Chin S, Pope D P. Metallurgical and Materials Transactions Ans A[J], 1979, 10A : 1323

19 Miner R V, Gabb T P, Gayda J et al. Metallurgical and Materials Transactions $A[\mathrm{~J}], 1986,17(3): 502$

20 Cong Peijuan, Hou Jieshan, Zhou Lanzhang et al. The Chinese Journal of Nonferrous Metals[J], 2011, 21: 747 (in Chinese)

21 Fleury E, Remy L. Materials Science and Engineering A[J], 1993, 167: 23

22 Yu Huichen, Li Ying, Zhang Guodong et al. Failure Analysis and Prevention[J], 2008, 3(1): 1 (in Chinese)

23 Golubovskiy E R, Svetlov I L, Petrushin N V et al. Russian Metallurgy (Metally)[J], 2010(10): 941

24 Ma Xianfeng, Shi Huiji, Gu Jialin et al. Acta Mech Solida Sin[J], 2008, 21: 289
25 Defresne A, Rémy L. Materials Science and Engineering $A[\mathrm{~J}]$, 1990, 129: 55

26 Hong S I, Laird C. Metallurgical Transactions A[J], 1991, 22: 415

27 Hong H U, Choi B G, Kim I S et al. Journal of Materials Science[J], 2011, 46: 5245

28 ASTM, Annual Book of ASTM Standards[S]. Philadelphia: ASTM, 1996

29 Nye F. Physical Properties of Crystals[M]. London: Oxford University Press, 1964

30 Landgraf R W. in: ASTM ed. Achievement of High Fatigue Resistance in Metals and Alloys[M]. Altantic City: ASTM Special Technical Publication, 1970: 467

31 Shui Li, Liu Ping. Rare Metal Materials and Engineering[J], 2015, 44(2): 288

32 Brundidge C L, Pollock T M. In: Eric R C R, Huron S eds. Superalloys 2012[M]. Pennsylvania, USA: TMS, 2012: 379

33 Murakami Y, Miller K J. International Journal of Fatigue[J], 2005, 27: 991

\title{
取向偏离度对镍基单晶高温合金 DD10 低周疲劳行为的影响
}

\author{
范志东 ${ }^{1,2}$, 李 季 $^{1}$, 王 栋 $^{2}$, 楼琅洪 ${ }^{2}$, 张 建 $^{2}$ \\ (1. 西安热工研究院有限公司, 陕西 西安 710054) \\ (2. 中国科学院金属研究所, 辽宁 沈阳 110016)
}

\begin{abstract}
摘 要：研究了特定试验条件下，镍基单晶 DD10 取向偏离[001]的程度对其低周疲劳行为的影响。结果表明：取向偏离度对 DD10 合金 的低周疲劳行为影响明显。疲劳寿命随取向偏离度的增加而明显降低, 在同等偏离度下, 晶体取向靠近[001]-[011]的合金低周寿命优于 取向靠近[001]-[11]的合金；分析发现：不同取向偏离度合金 DD10 低周疲劳寿命的差异源于其每循环周次的可累计塑性变形的差异。 另一方面, 取向偏离度对疲劳总应力幅和塑性应变幅的影响却截然相反，但对疲劳裂纹萌生和扩展方式影响不大。
\end{abstract}

关键词: 单晶高温合金; 合金 DD10; 取向偏离; 低周疲劳

作者简介: 范志东, 男, 1984 年生, 博士, 西安热工研究院有限公司, 陕西 西安 710054, 电话: 029-82002823, E-mail: fanzhidong@tpri.com.cn 